\title{
LA ESCOLARIDAD COMO HITO EN LAS BIOGRAFÍAS DE LOS HIJOS DE BOLIVIANOS EN BUENOS AIRES
}

\author{
Natalia Gavazzo* \\ Mariana Beheran** \\ Gabriela Novaro ${ }^{* * *}$
}

Este trabajo se propone un dialogo entre tres trabajos de investigación realizados desde perspectivas socio antropológicas aplicadas al análisis de las experiencias de los hijos de inmigrantes bolivianos en distintos puntos de la Ciudad de Buenos Aires y la Provincia de Buenos Aires. A partir del estudio de los procesos migratorios desde Bolivia y de sus cambios a lo largo de las generaciones, pretendemos postular que la escolaridad constituye parte fundamental de la experiencia de los niños y jóvenes migrantes y muy especialmente de los descendientes de inmigrantes bolivianos. Puesto que la misma afecta su formación intelectual, pero sobre todo, sus identificaciones nacionales, étnicas, de género, de clase y particularmente de edad, nos enfocaremos en comprender el rol de la escolaridad en esa etapa vital considerada como juventud. Teniendo en cuenta algunas de las representaciones mas habituales en los casos examinados, expondremos que el paso por la escuela primaria y secundaria implica un hito en las biografías de los hijos de los bolivianos y los niños y jóvenes bolivianos que se han criado en Buenos Aires y analizaremos el impacto en sus formas de identificación y sus relaciones.

Palabras clave: juventud, migración, educación, identificación.

\section{Introducción}

En este artículo presentaremos algunas reflexiones que se desprenden del trabajo de campo etnográfico correspondiente a investigaciones que hemos realizado en el marco de nuestras tesis doctorales ${ }^{1}$ y de investigación

\footnotetext{
*Universidad Nacional de San Martín. Buenos Aires/Argentina.

** Universidad Nacional Arturo Jauretche, Universidad de Buenos Aires. Buenos Aires/Argentina.

${ }^{* * *}$ Universidad de Buenos Aires. Buenos Aires/Argentina.

${ }^{1}$ BEHERAN, Mariana. "A la vida siempre le tuve curiosidad... Siempre quise aprender y hacer cosas pero mi deseo es volver a mi país". Intersecciones entre experiencias formativas, transiciones
} 
posdoctoral ${ }^{2}$, con la intención de reconstruir la complejidad de situaciones que atraviesan los hijos de bolivianos y los bolivianos criados en Argentina que residen en Buenos Aires. El análisis que presentaremos fue elaborado a partir de la contextualización e interpretación de la información que recabamos a través de múltiples registros y entrevistas. En este proceso hemos atendido continuamente a la visión construida por niños/as y jóvenes protagonistas de nuestras investigaciones, pero también a las imágenes y estereotipos que son asignados quienes interpelan sus identificaciones, especialmente en el ámbito escolar puesto que - como mostraremos - el mismo resulta preponderante en el relato de los niños/as y jóvenes.

Por un lado, la tesis de Beheran aborda, desde una perspectiva etnográfica, las intersecciones que tienen lugar entre las experiencias formativas escolares y familiares, las transiciones laborales y las identificaciones nacionales de jóvenes inmigrantes nacidos en Bolivia y Paraguay e hijos de inmigrantes procedentes de esos dos países, que viven en un barrio de la zona sur de la ciudad de Buenos Aires y que asisten a dos escuelas públicas de nivel medio ubicadas en él. En dicho trabajo se ha atendido a la emergencia de mandatos familiares y escolares, referidos a la escolaridad y transición laboral de los jóvenes. Asimismo, se ha observado que frente a estos mandatos los mismos elaboran distintas y cambiantes respuestas que se generan a través de múltiples condicionantes, entre los que se ubica el desarrollo de relaciones intergeneracionales más o menos conflictivas y la interdependencia de las categorías de género, etnia y clase social. Por último, se analizaron las transformaciones y/o continuidades de esos vínculos luego de que los jóvenes egresan del nivel medio ${ }^{3}$.

Por otro lado, la tesis de Gavazzo propone comprender la relación que existe entre las migraciones internacionales, las identificaciones y las formas de organización y participación, tanto individual como colectiva. En un nivel más específico, se analizan los modos en que los descendientes de bolivianos que residen en el $\mathrm{AMBA}$ se identifican en términos de identidad nacional, étnica, de clase, de género, entre otras, vinculadas al origen migratorio de sus padres. Dicho análisis adopta una perspectiva comparativa tanto entre generaciones como entre comunidades (bolivianos y paraguayos), entre barrios y organiza-

laborales e identificaciones nacionales de jóvenes inmigrantes, y descendientes de inmigrantes, en la ciudad de Buenos Aires; GAVAZZO, Natalia. Hijos de bolivianos y paraguayos en el área metropolitana de Buenos Aires. Identificaciones y participación, entre la discriminación y el reconocimiento.

2 NOVARO, Gabriela. Niños inmigrantes en Argentina: nacionalismo escolar, derechos educativos y experiencias de alteridad; IDEM (coord.). La interculturalidad en debate. Experiencias formativas y procesos de identificación en niños indígenas y migrantes; IDEM. Procesos de identificación nacional en población migrante: continuidades y quiebres en las relaciones intergeneracionales.

3 BEHERAN, op. cit. 
ciones. La misma luego examina los efectos que esas identificaciones tienen en las formas de participación social y política de estos descendientes a través de la exploración de, por un lado, sus maneras de auto-presentarse y percibirse como sujetos con derechos y como parte de la sociedad argentina/de la comunidad migrante de la que sus padres pueden ser parte, y por el otro de las políticas de identidad que se originan a partir de ellas y que se ven plasmadas en las acciones públicas de esta "segunda generación", y en diversos de los proyectos colectivos y organizaciones comunitarias en los que se involucran ${ }^{4}$.

Finalmente, el trabajo de Novaro refiere a la investigación que desarrolló entre el año 2004 y 2009, en escuelas primarias del barrio de Villa Lugano (al sur de la Ciudad de Buenos Aires) con una alta proporción de población migrante boliviana y, a partir del año 2010, en un barrio conocido como "Villa bolita", cercano a la localidad de Escobar (ubicada 50 kilómetros al norte de la Ciudad de Buenos Aires). En las escuelas de Lugano asisten niños procedentes de Bolivia habitantes de una de las mayores villas de emergencia de la ciudad. La población resulta fuertemente señalada en la escuela por su condición de residentes de la villa y sus experiencias de vida asociadas en gran medida con la migración. En el caso de Escobar, se trata de una investigación en curso entre familias y organizaciones de inmigrantes y escuelas de la localidad. El trabajo de campo se centró hasta ahora en el contacto con dos organizaciones - la Colectividad Boliviana de Escobar, y la Asociación de Mujeres Bolivianas de Escobar - con numerosas familias y con las dos escuelas primarias y secundarias del barrio. Se trata de dos situaciones en muchos sentidos semejantes y en otros claramente distintas. Entre estas diferencias vale destacar la región de origen de muchas de las familias (de la zona de Cochabamba en Lugano y de Potosí en Escobar), la inserción en el mercado laboral (en talleres y en la construcción en el primer caso; en la producción y comercialización hortícola y de vestimenta en el segundo), las características habitacionales (una villa de emergencia en Lugano y un barrio popular en Escobar).

La diversidad de contextos estudiados nos permite ponderar la variedad y complejidad de la situación de los jóvenes migrantes en Argentina. A pesar de algunas diferencias significativas registradas, identificamos también ciertas regularidades, Así, creemos posible postular que en todos los casos la escolaridad constituye parte fundamental de la experiencia de los niños y jóvenes migrantes y muy especialmente de los hijos de inmigrantes bolivianos. La misma afecta su formación intelectual pero sobre todo sus identificaciones nacionales, étnicas, de género, de clase y particularmente de edad. Por ello nos enfocaremos en comprender el rol de la escolaridad en esa etapa vital considerada como juventud.

${ }^{4}$ GAVAZZO, op. cit. 
Teniendo en cuenta algunas de sus representaciones más habituales en los casos examinados, expondremos que el paso por la escuela primaria y secundaria implica un hito en las biografías de la generación de los hijos de los bolivianos de Buenos Aires que afectara sus formas de identificación, sus relaciones con sus pares y con sus mayores, sean estos parientes o autoridades e instituciones.

Desde el punto de vista del fenotipo, por mencionar una de las formas de representar e imaginar a los inmigrantes, los bolivianos encuentran dificultades para "asimilarse" con la población del AMBA (que se auto-percibe como descendiente de europeos blancos o, como mucho, como migrante interno de algunas provincias, principalmente del norte del país). Paralelamente, si bien se trata de un colectivo hispanohablante - y "porteñohablante" en particular - las tonadas también constituyen marcas que evidencian pertenencia. De modo que aunque la sociedad considera que los hijos son "extranjeros" o "inmigrantes" o "bolivianos", incluso cuando jurídicamente no lo sean, esta situación interpela a estos sujetos de modos diferenciales según las posibilidades de éxito para "desmarcarse" de esa afiliación ${ }^{5}$. La lengua y el cuerpo operan como diacríticos diferenciales que movilizan diferentes estrategias de negociación de la identidad y hacen que los hijos de bolivianos en Buenos Aires puedan considerarse como parte de una misma generación a pesar de sus heterogéneas formas de identificación ${ }^{6}$.

\section{Algunos aportes del estudio de la generación de los hijos de inmigrantes}

El tema de la segunda generación de inmigrantes se ha convertido ciertamente en un problema social y en un problema de investigación relevante dentro del campo de estudios migratorios. El hecho de que en las escuelas haya cada vez más niños y jóvenes migrantes o hijos de inmigrantes, en esas sociedades que se han auto-representado e imaginado como "una comunidad predominantemente blanca"7, no constituye un dato menor. En Estados Unidos, por ejemplo, donde se estima que uno de cada cinco niños menores de 18 años puede ser considerado como "segunda generación", el asunto se ha convertido en el centro de las preocupaciones tanto de políticos y estudiosos de las migraciones como de las propias poblaciones migrantes ${ }^{8}$. Allí se incluyen dentro de esta noción tanto a la denominada "generación uno y medio $(1,5)$ ", es decir el grupo de los que emigraron a temprana edad pero fueron criados

5 GAVAZZO, op. cit.

${ }_{6}$ El trabajo realizado permitió registrar el modo diferencial en que esto se juega en distintos colectivos migrantes. En este artículo solo hacemos mención a los procedentes de Bolivia y a sus hijos.

LEVITT, Peggy e WATERS, Mary. The Changing Face of Home. The Transnational, p. 1.

8 Ibidem, p. 2. 
y crecieron en la sociedad de destino, como los nacidos directamente en otro territorio nacional (a los que denominamos "hijos" en este trabajo). En estas definiciones, aparece un grupo - en este caso, una generación - que puede ser visible porque sus miembros son parte de un conjunto definido y "marcado" como inmigrante más allá de su nacionalidad o lugar de nacimiento.

En Estados Unidos y España diversos estudios analizaron problemas de "integración" de los niños y jóvenes inmigrantes e hijos de inmigrantes en los espacios escolares ${ }^{9}$. Particularmente nos interesa considerar el trabajo de Portes ${ }^{10}$ en tanto advierte sobre las dificultades que experimentan los hijos para crecer en una familia de inmigrantes en tanto buscan equilibrar la orientación de los padres extranjeros con las demandas de "asimilación" de la sociedad receptora. Así, la "segunda generación" vive la tensión entre ambas expectativas, lo que puede culminar o bien en el rechazo de la cultura parental o bien en un repliegue hacia adentro de la comunidad migratoria para no confrontar con la sociedad exterior.

En cuanto a las situaciones que estudiamos, debe señalarse que la mayor parte de los hijos de inmigrantes residentes en la Ciudad de Buenos Aires y en la Provincia de Buenos Aires no son los hijos de europeos muchos de los cuales ascendieron socialmente y entraron en los circuitos de "legitimación cultural formal". Ahora son los hijos de los inmigrantes limítrofes y despiertan representaciones, discursos y normativas bien diferentes a sus antecesores ${ }^{11}$. Sin embargo, en la actualidad aún prevalece el imaginario de que todos los argentinos "descendemos de los barcos", invisibilizando tanto las adversidades que padecieron muchos de aquellos inmigrantes europeos como la historia y presencia de pueblos indígenas y de inmigrantes procedentes de países limítrofes. De modo que resulta central examinar los modos en que los descendientes de estos últimos se definen públicamente como "problema social", para luego comprender mejor las relaciones familiares y especialmente la "subjetividad de los hijos", es decir sus formas de identificación.

Por esta razón, resulta importante examinar lo que el término "inmigrantes de segunda generación” representa, cómo se transmite y reproduce, para

9 Entre otros, PORTES, Alejandro (ed.). The Economic Sociology of Immigration. Essays on Networks, Ethnicity and Entrepreneurship; PORTES, Alejandro e RUMBAUT, Rubén. Immigrant America: a portrait; IDEM. Legacies: the Story of the Immigrant. Second Generation; PORTES, Alejandro e ZHOU, Min. En route vers les sommets: nouvelles perspectivas sur la question des minorités ethniques; LEVITT, WATERS, op. cit.; FONER, Nancy. Introduction: Intergenerational Relations in Immigrant Families; GARCÍA BORREGO, Iñaki. Los hijos de inmigrantes extranjeros como objeto de estudio de la sociología.

${ }^{10}$ PORTES, op. cit.

11 Según el Censo de 2010 casi el 70\% de la población extranjera residente en la Argentina es nacida en otros países de la región, especialmente en limítrofes como Bolivia y Paraguay que juntas, (con más de 330.000 la primera y más de 550.000 la segunda), constituyen casi la mitad del aproximadamente $4 \%$ de la población total del país a la que se define como "inmigrantes". 
entender las implicancias de esa denominación aplicada a los hijos que nunca inmigraron. Pues esta forma de clasificar unifica a padres e hijos dentro de la categoría común de "inmigrantes", y los opone a los "autóctonos", lo que de diversas maneras sustenta su estigmatización. De este modo, el estigma pareciera transmitirse "de generación en generación". A ese respecto, retomando trabajos anteriores ${ }^{12}$ en este escrito proponemos utilizar la categoría "hijo" por considerarla más pertinente, no sólo por ser la de uso "nativo" más extendido, sino también para superar este sesgo discriminatorio que la noción de "segunda generación" puede esconder. Con bastante claridad, esta situación representa un desafío considerable no sólo para los hijos sino también para quienes emprendan un análisis de sus diversas estrategias de "asimilación" o "integración", ya que postula como central el plano cultural para comprender las formas de inclusión de los grupos de inmigrantes en la sociedad receptora. Con relación a esta problemática la antropología puede realizar un aporte sustancial.

Ahora bien, resulta significativo que aunque la migración boliviana a la Argentina cuenta con una historia que abarca ya varias décadas y generaciones, aparentemente el tema de las "segundas generaciones" aun no ha sido explorado del mismo modo que lo fue para otros flujos de inmigración, como el de los descendientes de inmigrantes provenientes de $\mathrm{Asia}^{13}$ y Europa ${ }^{14}$. Por esta razón, se debe recurrir tanto a los estudios realizados para otras comunidades en Argentina (como los mencionados más arriba) como para otros migrantes en el mundo ${ }^{15}$.

A partir de los años noventa, a nivel nacional se desarrollaron una serie de estudios sobre la escolaridad de los niños inmigrantes e hijos de inmigrantes. Esos trabajos destacaron la persistencia de prácticas educativas vinculadas al paradigma asimilacionista y a discursos escolares nacionalistas y la aparición de miradas docentes positivas respecto de la diversidad cultural, asociadas al paradigma del multiculturalismo. Paralelamente, dieron cuenta de las prácticas estigmatizantes y xenófobas y las diversas formas de exclusión social que padecía esa población en algunas escuelas ${ }^{16}$. Los trabajos abocados

12 GAVAZZO, op. cit.

${ }^{13}$ LAMOUNIER, I. Japanese Argentina Historial Overview; ONAHA, Cecilia. Japoneses en Argentina y nikkei argentinos en Japón: el rol de la identidad nacional y étnica en un proceso de integración de los nikkei argentinos en Okinawa; GOMEZ, S. Historias Nikkei, historias transnacionales.

${ }^{14}$ DEVOTO, Fernando. Historia de la inmigración a la Argentina; MALUENDRES, Sergio. De nuevo sobre las pautas matrimoniales de los migrantes y sus hijos piamonteses y leoneses en Trenel, Territorio Nacional de La Pampa, (1911-1940).

${ }^{15}$ Entre otros, PORTES, op. cit.; SAYAD, Abdelmalek. La doble ausencia. De las ilusiones del emigrado a los padecimientos del inmigrado; GARCÍA BORREGO, op. cit.; PEDONE, Claudia. Introducción. Más allá de los estereotipos: desafíos en torno al estudio de las familias migrantes; PEDREÑO CANOVAS, Andrés. Carrera y fracaso en las trayectorias sociales de los hijos de inmigrantes.

${ }^{16}$ NEUFELD, María Rosa e THISTED, Ariel (comps.). De eso no se habla: los usos de la diversidad sociocultural en la escuela; DOMENECH, Eduardo. Etnicidad e inmigración: ¿Hacia nuevos modos 
a la escolaridad de inmigrantes en el nivel medio todavía son escasos. La mayor parte de ellos ha analizado las prácticas discriminatorias que tienen lugar en ese nivel respecto de los estudiantes inmigrantes y la normativa referida a la escolaridad de dichos jóvenes.

La escasez de estudios sobre esta población a nivel nacional se condice con la invisibilización de la temática en las políticas públicas. A nivel nacional las propuestas referidas a una educación intercultural tuvieron lugar en el marco de programas compensatorios, entendiendo a la diversidad cultural en términos de desventaja educativa ${ }^{17}$. Si bien en el año 2006, a partir de la sanción de la Ley de Educación № 26. 206 se creó la modalidad de Educación Intercultural y Bilingüe en distintas jurisdicciones y el área comenzó a formar parte de la Dirección de Gestión Curricular del Ministerio de Educación de la nación ${ }^{18}$, en la política nacional la misma continúa referida a la situación de la población indígena sin contemplar dentro de las problemáticas a abordar la presencia de estudiantes inmigrantes en los distintos niveles del sistema educativo y las necesidades educativas de esta población.

Asimismo, es menester rescatar los aportes provenientes de la antropología respecto de "lo generacional" puesto que, también desde épocas tempranas, existía en la disciplina una preocupación por los estudios sobre alteridad etaria, grupo de edad y generación, es decir sobre "la edad como dimensión estructurante de la práctica social"19. A partir de estos aportes, podremos apreciar cómo la edad, como construcción cultural, opera "naturalizando asimetrías y relaciones de poder e interpela la agencia de los sujetos puesto que es el lenguaje de las relaciones familiares el que establece las relaciones entre los grupos de edad"20. Así, las relaciones de parentesco, la familia, la unidad doméstica y - en trabajos más actuales - los hogares o viviendas forman parte de los temas más estudiados en la tradición del trabajo de campo etnográfico. Estos estudios constituyen una importante contribución a la comprensión de nuestros casos de estudio al prestarle atención a las prácticas sociales de la generación de los "hijos" como sujetos plenos igualmente dotados de capacidad reflexiva y competencia cultural.

de integración en el espacio escolar?; BEHERAN, Mariana. El tratamiento de la diversidad cultural en las escuelas públicas primarias de la ciudad de Buenos Aires; DIEZ, María Laura e NOVARO, Gabriela. Interculturalidad en educación: ¿un abordaje para la crítica? Reflexiones a propósito de la escolarización de chicos migrantes bolivianos en Buenos Aires; MARTINEZ, Laura. Discursos sobre la migración en el contexto escolar: una exploración de las relaciones entre las prácticas institucionales y las concepciones de los niños migrantes.

${ }^{17}$ BORDEGARAY, Graciela; NOVARO, Gabriela. Diversidad y desigualdad en las políticas de Estado. Reflexiones a propósito del proyecto de Educación Intercultural y Bilingüe en el Ministerio de Educación.

${ }^{18}$ DIEZ, María Laura et alii. Interculturalidad y educación. Cruces entre la investigación y la gestión.

${ }^{19}$ KROPFF, Laura. Apuntes conceptuales para una antropología de la edad.

20 Ibidem, p, 25. 
Como veremos, el término generación tiene numerosos sentidos y abarca entonces desde las relaciones entre padres e hijos hasta las que se dan entre los distintos grupos de edad ${ }^{21}$. En este sentido existen varios estudios que provienen de un campo de estudios sobre juventudes que constituyen una base interesante para analizar las cuestiones aquí planteadas ${ }^{22}$. El tema de las edades y las juventudes ha sido abordado a partir del trabajo de campo en barrios con una perspectiva atenta a las relaciones de $\operatorname{poder}^{23}$. Asimismo, existen estudios realizados sobre las relaciones intergeneracionales en las familias ${ }^{24}$ que también serán retomados para indagar en los sentidos del término generación que nos permitan definir al grupo de descendientes en estudio.

Respecto de la generación genealógica, las identificaciones de los hijos se pueden comprender dentro de la estructura de la familia migrante. En ese sentido, podría decirse que existen dos subcampos de estudios académicos sobre migración: la primera es la teoría de la asimilación segmentada ${ }^{25}$ que se enfoca en los "patrones de adaptación" de los migrantes contemporáneos y sus descendientes. Estos patrones van de la "aculturación" (con inclusión en la clase media) hasta la "movilidad social descendente" (con incorporación a las clases bajas) y el "avance económico a través de la preservación de los trazos étnicos únicos" (que puede implicar asimismo incorporación a la clase media). La segunda vertiente teórica es la del transnacionalismo, es decir un conjunto de estudios que se enfocan en los tipos de lazos que los migrantes contemporáneos mantienen con sus países de origen. Estos estudios muestran que un creciente número de inmigrantes sostienen lazos económicos, políticos y religiosos con sus países de origen mientras trabajan, votan y rezan en los países que los han recibido ${ }^{26}$. Desde esta perspectiva, el interés está puesto sobre las prácticas transnacionales de los hijos de los inmigrantes ${ }^{27}$.

${ }^{21}$ BOURDIEU, Pierre. Algunas propiedades de los campos; IDEM. La distinción. Criterios y bases sociales del gusto; MANNHEIM, K. El problema de las Generaciones.

22 Entre otros, MARTÍN CRIADO, Enrique. Producir la juventud: crítica de la sociología de la juventud; IDEM. "Generaciones/clases de edad" y "Juventud". KROPFF, Laura. Activismo mapuche en Argentina: trayectoria histórica y nuevas propuestas; CHAVES, Mariana. Juventud negada y negativizada: representaciones y formaciones discursivas vigentes en la Argentina contemporánea.

${ }^{23}$ ELIAS, Norbert. La civilización de los padres; ELÍAS, Norbert e SCOTSON, John. Os Estabelecidos e os Outsiders.

${ }^{24}$ Tales como DONZELOT, Jacques. La policía de las familias; LEVITT, Peggy. Los desafíos de la vida familiar transnacional. LEVITT, WATERS, op. cit.

${ }_{25}$ PORTES, ZHOU, op. cit.

${ }^{26}$ LEVITT, WATERS, op. cit. p. 2.

27 Ambas corrientes, analizadas en detalle en Gavazzo (op. cit.), resultan útiles para dar cuenta de las formas heterogéneas en que los hijos de bolivianos se identifican como parte de una generación (la de los hijos de padres migrantes) y de los modos en que sus visiones de mundo se asemejan y/o difieren de la de sus padres. 


\section{La familia migrante: expectativas de los padres y educación de los hijos}

Como detallamos en el punto anterior, existen numerosos estudios realizados acerca de familias migrantes en distintas partes del mundo, especialmente en Estados Unidos y Europa en los últimos diez o quince años. En ellos, suele afirmarse que "crecer en una familia de inmigrantes siempre ha sido un proceso difícil en el que se deben reconciliar la orientación en el lenguaje y la cultura de los padres extranjeros con las demandas de asimilación de la sociedad receptora" ${ }^{28}$. Así, los niños migrantes o hijos de inmigrantes parecen encontrarse con un dilema personal: si "se mantienen" parecidos a sus padres en nuestros casos "bolivianos"- se enfrentarán al ostracismo social y posiblemente experimenten dificultades en su integración en la escuela, pero si "se convierten" en locales -"argentinos" para nosotros - deberán "alejarse de los sueños de sus padres de progresar sin perder la solidaridad étnica y la preservación de valores tradicionales"29. Ahora bien ¿cómo se presentan las tensiones en las relaciones familiares en el caso de los hijos de bolivianos en el AMBA?

Las expectativas de las familias con respecto a la escolaridad deben ser analizadas considerando la diversidad de contextos en los que la población migrante se inserta. Hemos trabajado en distintos espacios bastante contrastantes en este sentido ${ }^{30}$. En el trabajo en escuelas primarias del barrio de Lugano el contacto con las familias fue puntual (charlas informales en la entrada y la salida de la escuela y en actos escolares, entrevistas biográficas a algunos padres de los niños con los que trabajábamos). Recordemos que los niños habitan una villa de emergencia con numerosas asociaciones vecinales, vinculadas a partidos políticos, pero donde los colectivos migrantes no han consolidado formas organizativas propias que se proyecten con continuidad y capacidad de convocatoria.

En estas situaciones la demanda más clara y consensuada de las familias con las que dialogamos se expresaba en las expectativas de que la escuela sea más ordenada, no se admitan situaciones de indisciplina, falta de respeto, golpes e insultos. La legitimación de este reclamo se sostenía en el recuerdo de una escolaridad más disciplinada en Bolivia, donde los relatos exaltaban el clima de orden, deslizándose hacia el recuerdo de distintas formas de castigo.

En Escobar, realizamos el registro de las expectativas de las familias en un contexto muy distinto y donde además nos conectamos con las familias antes de

${ }^{28}$ PORTES, op. cit., p. 248.

${ }^{29}$ Ibidem, p. 244.

${ }^{30}$ Este punto ha sido trabajado en textos anteriores: NOVARO, Gabriela e DIEZ, María Laura. ¿Una inclusión silenciosa o las sutiles formas de la discriminación? Reflexiones a propósito de la escolarización de chicos bolivianos; NOVARO, Gabriela (en prensa). Procesos de identificación nacional en población migrante: continuidades y quiebres en las relaciones intergeneracionales. 
ir a las escuelas. En este espacio, como se explicitó antes, destaca el fuerte proceso asociativo y la relevancia de organizaciones como la Colectividad Boliviana de Escobar y también asociaciones de mujeres migrantes. En principio resulta significativo que en este contexto se reiterara la demanda de que en la escuela haya mayor orden y respeto y la asociación inmediata que en el discurso se hacía entre esta expectativa y el recuerdo de una escolaridad más ordenada en Bolivia.

En otros trabajos hemos reflexionado detenidamente en torno a los múltiples sentidos que se juegan en estas demandas disciplinadoras en un contexto de fuertes quiebres en la transmisión intergeneracional.

Encontramos en esta localidad situaciones que hablan claramente de la preocupación de las familias por la educación: estrategias para inscribir a los niños en la escuela que se considera más prestigiosa, esfuerzos por mantener a los niños en la escuela aún en situaciones económicas muy vulnerables, apuesta por que los niños y jóvenes realicen trayectorias escolares largas, preocupación porque hablen bien el castellano, angustia por no poder ayudarlos en las tareas, denuncia de situaciones de discriminación en la escuela, etc. En general registramos en los padres una fuerte apuesta por la inclusión educativa en condiciones de mayor igualdad que las que ellos vivieron.

Pero, a diferencia de la situación anterior, en esta localidad registramos iniciativas direccionadas hacia la conformación de espacios escolares "propios" sostenidas por las familias y también por las asociaciones. Por ejemplo, el seguimiento del proyecto de creación de una escuela "propia" "que tenga lo boliviano y también lo argentino", "que los maestros sean paisanos" da cuenta de la dificultad para concretar instancias que articulen expectativas y demandas de la población migrante con el sistema educativo y posiblemente también, habla de una historia con fuerte presencia de proyectos educativos paralelos a la educación estatal en Bolivia; en definitiva, muestra la compleja vinculación de las organizaciones con el Estado en el contexto migratorio. El tema fue planteado en numerosas asambleas de socios de la colectividad pero al día de hoy sigue sin resolverse y siendo motivo de división entre quienes apuestan por un establecimiento privado que les permita mantener mayor autonomía y quienes dudan de la viabilidad de esta propuesta.

En estas expectativas y demandas de las familias hacia la escuela, en las propuestas escolares propias y en general en las actividades a las que se convoca a los niños y jóvenes y que funcionan como fuertes marcantes de nacionalidad (integración de conjuntos de danza, de bandas, participación en actividades deportivas, etc.) se advierte una fuerte apuesta de las familias y organizaciones porque los niños nacidos en Bolivia y criados en Argentina y también los hijos de migrantes sigan, de alguna manera, identificados con lo boliviano. 
Resultan también significativos los atributos asociados a la idea de niño y sujeto boliviano, caracterizado en el discurso de familias y organizaciones como obediente, tranquilo y en ocasiones sumiso. Para comprender la valoración de estos rasgos hay que ubicar estas expectativas en un contexto vivido como violento, en permanente cambio, de lazos en constante peligro de disolución

Las imágenes de sujeto y en concordancia con ellas, las expectativas hacia la educación y la escuela parecen desplegarse en este contexto en relación a la tensión entre continuidad y cambio, asociado a representaciones sobre "lo boliviano" y "lo argentino" caracterizados a partir de atributos vinculados a la dualidad tradición-modernidad. Lejos de valoraciones fijas y constantes, junto con el deseo de inclusión en lo que se asocia a lo nuevo, se registra la nostalgia por la continuidad y la tradición, la tranquilidad y la confianza atribuidos a Bolivia, que se opone a las imágenes de inseguridad y desconfianza vinculadas a Argentina.

En la investigación doctoral de Beheran ${ }^{31}$ se atendió a las relaciones intergeneracionales que se construyen entre padres, madres y jóvenes inmigrantes o hijos de inmigrantes, más específicamente a los mandatos familiares referidos a la educación y el trabajo y a las variadas formas en que los jóvenes vivencian esos mandatos. Contrariamente a lo observado por Novaro en familias bolivianas cuyos hijos asisten al nivel primario, las familias cuyos hijos asisten al nivel medio parecieran tener una visión menos crítica respecto de la escolaridad de sus descendientes. Ahora bien, en numerosas ocasiones, más allá de la importancia que las familias migrantes bolivianas le otorgan a la educación formal, la cual fue manifestada por ellas a través de varias conversaciones informales y entrevistas, las complejas situaciones de desigualdad social que atraviesan sus vidas las llevan a intentar convencer a sus hijos, y en ocasiones a obligarlos, para que trabajen junto a ellas en actividades cuya formación habían recibido, generalmente, en sus hogares (trabajo textil). Contrariamente a lo que las familias habían imaginado durante la elaboración de sus proyectos migratorios, los jóvenes debían combinar sus estudios con el trabajo, o bien interrumpirlos. En la mayor parte de las trayectorias analizadas, se trataba de trabajos en el ámbito del hogar o bien en espacios laborales que se encontraban asociados a la colectividad de origen de las familias y que se caracterizaban por la explotación laboral.

Por su parte, la investigación doctoral de Gavazzo $^{32}$ ha evidenciado que es común que los inmigrantes declaren que el motivo de la emigración es "darle una mejor vida a mis hijos", "una educación mejor" o "una salud de calidad".

\footnotetext{
${ }^{31}$ BEHERAN, "A la vida siempre..., op. cit.

${ }^{32}$ GAVAZZO, op. cit.
} 
Frecuentemente esto se traduce en una presión para que los hijos rindan en la escuela, en ocasiones mucho más compañeros; se registran también las dificultades para satisfacer esas expectativas ${ }^{33}$. Cuando las expectativas de los mayores con respecto al "futuro educacional y profesional" de los menores que tienen a cargo es alta, se generan tensiones intergeneracionales al interior de la familia. En cuanto al énfasis de los mayores en la educación de los hijos, es posible afirmar que - en ocasiones - la inserción de los padres depende del éxito escolar de sus hijos, especialmente si los primeros no hablan el idioma nativo. En estos casos, los hijos se convierten en traductores e, incluso, pueden sentirse "avergonzados" por la incapacidad de sus padres de realizar tareas básicas como llenar un formulario o realizar una consulta médica.

Si bien las fuentes de tensión intergeneracional pueden ser diversas, ciertamente una de ellas es la "disciplina" y el "respeto" que, en ocasiones, es solicitado de un modo más intenso en las familias migrantes que lo que se espera en la sociedad de destino lo que incluso, desde la visión de ésta última, puede parecer "abusivo" y "autoritario"34. Los padres suelen creer que las pautas de crianza en las sociedades de destino hacen que sus hijos sean irrespetuosos y groseros. De esto resulta que "cuando los padres se sienten frustrados y amenazados por los nuevos valores y comportamientos a los cuales sus hijos están expuestos, intentan ajustar su dominio, lo que, como resultado, aumenta el resentimiento de los hijos y el deseo de eludir el control parental" 35 . Esto puede observarse en cuanto a las relaciones sexuales y a las citas, lo que nos lleva a otra fuente de tensión: la presión de algunos padres para que los hijos se casen con otros connacionales o sus descendientes.

\section{El punto de vista de los hijos: identificaciones dobles entre el estigma y el orgullo}

El paso por la escuela adquiere en los relatos de los hijos de migrantes un lugar clave en su construccion identitaria. Entre diversas alusiones, se reiteran aquellas que dan cuenta de la percepción de "ser diferentes":

Gustavo B tiene 39 años y sus padres son bolivianos. Nació y vivió hasta hace algunos años en el barrio Charrúa de la CABA que contiene una gran población de ese origen. Según comenta, sus padres lo enviaron a una escuela "fuera del barrio" porque querían que tuviese una "mejor educación". A pesar de que quedaba relativamente cerca de su casa (en Pompeya) aparece como "del otro lado" de una frontera que dividía dos

\footnotetext{
${ }^{33}$ FONER, op. cit.

34 Ibidem.

${ }^{35}$ Ibidem, p. 5.
} 
espacios diferenciados y jerarquizados, y que, aparentemente, marcaba también el espacio del aula: "Yo iba a una escuela que está ahí a 4 cuadras del barrio, una escuela privada, religiosa, de franciscanos, ahí éramos 4 o 5 que íbamos a esa escuela de Charrúa, me acuerdo que nos sentábamos todos juntos porque decían "éstos? Qué raros!" (...).

Ciertamente las fronteras en el espacio escolar denotan la presencia de otras fronteras simbólicas y materiales, entre las cuales la casa y la escuela pueden constituir uno y otro de sus lados. Esto tendrá efectos en las identificaciones de los hijos, puesto que las relaciones sociales pueden estructurarse en torno a ellas de modo que "unos" quedan de un lado y "otros" del otro. Sin embargo, algunos hijos que asisten a escuelas "distantes" (en el sentido del grado de percepción de la otredad) hacen el camino hacia ambos lados de esas fronteras más allá de que para algunos esa separación se perciba como infranqueable. Como indica Gustavo B: "yo de chico era la escuela, la casa, Charrúa, los vecinos y de vez en cuando alguna salida (...) en la escuela primaria yo creo que sin darse cuenta las maestras también hacían, el trato era otro con nosotros, yo lo notaba, yo desde chico fui muy observador, pero yo me daba cuenta de que la cosa era diferente"

Aunque Gustavo era un buen alumno ("nerdy" en sus propias palabras), nunca pudo "desmarcarse" del supuesto origen étnico familiar: "Yo recuerdo aquel compañero con el que competíamos mucho, él era el mejor promedio de los blancos (...) mis amigos me decían: de los blancos era Hernán y de los negros era yo (... $)^{36}$.

A pesar de situaciones de discriminación en las escuelas, debe mencionarse que una parte considerable de los entrevistados no reconoce haber atravesado experiencias de discriminación directa en su vida escolar. Mercedes tiene 29 años, nacida en Buenos Aires y de padres bolivianos, es vecina de Pompeya y reconoce que su experiencia no es la misma que la de muchos de estos amigos porque:

(...) En la escuela nunca sentí discriminación (...), para mi yo en la escuela era argentina, no había necesidad de de que me digan boliviana, o hija de boliviana (...) no sentí (discriminación) porque iba a un colegio pupila y a la vez también era un colegio de monjas, no existía tampoco eso, porque -es mas- había hijas de gente del Paraguay o sea que no sentíamos en ésa época (...).

\footnotetext{
${ }^{36}$ Como decíamos en la introducción, es importante resaltar la "racialización" de la diferencia entre aquellos que "portan" rasgos indígenas (tanto en sus atributos físicos como en sus comportamientos sociales). Si el cuerpo es la marca de gran parte de los bolivianos que residen en el AMBA, la lengua lo es en el caso de los paraguayos, y es por esta razón que los primeros generalmente tienen menos posibilidades de desmarcarse haciendo que su visibilización sea un hecho casi ineludible (GAVAZZO, op. cit.).
} 
Sin embargo, Mercedes opina que muchos hijos no quieren aprender de la cultura de su familia por vergüenza (y así "niegan el origen") e incluso algunos hijos discriminan a sus propios padres. Tal como se analiza en la tesis mencionada ${ }^{37}$, ciertamente el grado de violencia varía en cada situación de discriminación, pero parece posible pensar que si la persona es interpelada como "boliviana", en tanto se percibe que responde (por el cuerpo, por la lengua, por el comportamiento) a esa construcción, el estereotipo negativo conlleva un trato inferior o agresivo.

Ahora bien, algunas acciones de "marcación" resultan más ambivalentes en cuanto al estigma, como cuando se afirma que los hijos de los migrantes tienden a ser más "callados" y "tímidos" que los otros alumnos ${ }^{38}$. En todo caso, la "marcación" como visiblemente diferentes, se incrementa cuando el niño va a una escuela en donde no encuentra a otros "iguales". Justamente los estereotipos son frecuentemente apropiados y actuados por los mismos niños en sus trayectorias escolares. Como veíamos, Gustavo B se auto-define como "de los negros". Por su parte, Nancy, que tiene 22 años, es hija de ambos padres bolivianos que, a diferencia de los padres de Gustavo B, provienen de zonas rurales del Departamento de Potosí. Actualmente estudia en la universidad la carrera de Historia y trabaja en un puesto de venta de verduras cerca de su casa en áreas peri-urbanas de la ciudad. Según cuenta, "mi viejo no quería que laburara; hasta hoy en la universidad mi viejo lo que quiere es que yo termine de estudiar y no labure". Como Gustavo B, asistió a una escuela "lejos de casa" (en su caso "en el centro") en donde directamente no había otros hijos de migrantes como ella. Desde su percepción esto marcó su carácter y su modo de ser en toda la época escolar y en los años posteriores:

Cuando era más chica me pisaban en todos lados, te juro. En el negocio sí; me ha pasado un montón de veces; por ahí no me sabía los precios; me ponía nerviosa y los comentarios, así, aunque sea en voz baja, me dolían, me llegaban. Y yo no les decía nada. O, por ahí, en la escuela, que ahí fue más fuerte; me insultaban y me hacía la que no escuchaba. Y no me defendía; no sé, era tan ... Era como que sentía que reproducía eso que le pasaba a mi viejo pero conmigo.

Es interesante, advertir que la percepción de Nancy sea que carga con un estigma que "proviene" de su padre y pasa a ella como una "herencia" que se expresa mediante su tolerancia a ese mismo acto de violencia.

\footnotetext{
${ }^{37}$ GAVAZZO, op. cit.

${ }^{38}$ NOVARO, Gabriela; BORTON, Laureano; DIEZ, María Laura; HECHT, Ana. Sonidos del silencio, voces silenciadas. Niños indígenas y migrantes en escuelas de Buenos Aires.
} 
En este contexto, se registran numerosas experiencias e iniciativas de docentes y directores de escuela, intentos de intervenir en situaciones de discriminación, realizar actividades pedagógicas en el aula y visitas a exposiciones de museos, entre otras. Si bien estas actividades ofrecen un espacio para la generación de imágenes positivas, la alterización parece operar cuando los "hijos" no pueden desmarcarse como diferentes a los nativos "puros". La marcación parece enfocarse tanto en los niños migrantes como en los hijos de inmigrantes. Es por eso que, a pesar de que según sus relatos no han sido discriminados, casi todos los entrevistados dejan constancia de conocer experiencias discriminatorias de modo indirecto en al menos un caso en la familia.

En este sentido, puede observarse una amplia gama de reacciones frente a este contexto hostil que hace que cumplir con las expectativas de los padres bolivianos se vuelva complicado ${ }^{39}$. Existe un recorrido que va de la negación de la discriminación ("a mi nunca me discriminaron") y la auto-desvalorización ("ellos no son malos") hasta el "pasar como" (en el sentido goffmaniano de transformar la apariencia física, el habla y la vestimenta para alejarse del estereotipo estigmatizado), la reacción violenta (hacia otros argentinos o hacia sus propios padres como mencionábamos en la parte anterior) y la guetificación ${ }^{40}$. El principal unificador de esta diversidad es el hecho de que tanto padres como hijos comparten una cierta imagen pública, ciertas representaciones, en el caso analizado, cierta estigmatización.

Esto se observa en el relato de Nancy quien confiesa que prefería quedarse en el barrio a "salir" de él por miedo a los ataques y por vergüenza a que los "otros" pudieran averiguar su origen:

Te juro; me paraba 10 cuadras antes, al lado del timbre, porque yo no salía nunca de "mi huevito", que era mi barrio; ése era mi mundo. Y cuando empecé a ir a la secundaria, (...) no la pasé muy bien; en 8o y 9o; ahí yo era la única hija de bolivianos, en toda la escuela. (...) Yo me acomodaba porque estaba en los 2 espacios; en el barrio, con mis amigas que me contaban todo lo que ellas vivían y yo, lo que vivía en otras escuelas; eran muy diferentes, por ahí, pero estaban los 2 espacios; como que me sentía por ahí, a lo último me terminé sintiendo más extraña en mi propio barrio porque yo estaba todo el día en la escuela.

Gustavo B también hizo la primaria y la secundaria en "el centro" pero cerca de "su" barrio Charrúa en donde siempre encontró refugio. De todos modos, la frontera entre un espacio y el otro siempre la sintió de modos muy

39 GAVAZZO, op. cit.

${ }^{40}$ IDEM. Para todos los hombres del mundo: diversidad cultural y nación en algunos discursos públicos sobre la inmigración en Argentina. 
concretos: "Me daba cuenta cuando yo iba a la casa de un compañero, yo sí podía ir a la casa de un compañero, ellos no podían venir, porque era una cosa como que no, Charrúa no voy (...) A mi casa nunca vino nadie".

Esto reforzó su aislamiento o, al menos, la sensación de que vivía entre un mundo privado (el del barrio y la casa familiar) y otro público (la escuela y sus compañeros). En esto existe una certeza del lugar al que supuestamente los hijos "pertenecen" que es el ámbito de los migrantes aunque para los padres los hijos deben superar ese límite para poder "progresar". Entre ambos espacios Gustavo percibe no sólo una frontera que divide a los diferentes sino sobre todo a los desiguales:

era como que iba y venía a dos mundos (...) claro porque iba estaba en un mundo que era de todos porteños (...) me acuerdo el trato de las madres de los chicos, en los autos, viste así, cuando había que poner plata para el regalo de la maestra, a nosotros ni nos pedían, porque sabían que no poníamos, no teníamos, y siempre nos hacían a un lado, se generaba algo raro.

En estos espacios, la concentración de familias bolivianas y las prácticas de identificación contribuyen a lo que podría denominarse proceso de guetificación, ya que en muchos casos la red de contactos se restringe exclusivamente a los connacionales (incluso de la misma región de Bolivia) que residen en la misma área urbana. Asimismo, esto "visibiliza" a los migrantes en el espacio urbano que es donde se relacionan con "otros" habitantes de la ciudad. Por todo esto, se supone que la mayoría de los hijos e hijas de inmigrantes asumirán primordialmente las normas e instituciones de donde son criados. Sin embargo, algunos hijos que están más profundamente imbricados en campos sociales transnacionales no elegirán simplemente entre el lugar de origen y el de recepción. En lugar de esto, intentarán de alguna manera integrar ambos espacios a su vida cotidiana.

Los consumos culturales son también "marcas diferenciales" entre los hijos, y mientras que en el "afuera" las mismas pueden constituir la base de la estigmatización, en el barrio en donde residen muchas familias del mismo origen se convierten en motivo de orgullo y en guiño cómplice "entre iguales". Dentro de estos espacios, según comentan los hijos, se podría gozar de una suerte de "barrera" que -entre otras cosas- los protege de la discriminación. Tal como dice Gustavo B - en concordancia con el relato de Consuelo -:

...ahí en Charrúa nadie te va a venir a decir boliviano de mierda, nada, te cagan a palos, pero afuera sí te lo dicen... entonces vos decís, que onda digo o no digo que soy hijo? Yo siempre lo tuve claro, siempre lo dije...en la adolescencia, como que, fue menos traumática...lo teníamos tan manejado de la 
primaria que no había problemas... la secundaria la viví menos traumáticamente... lo vivía como un plus, siempre... para mi es un plus, lo siento así y lo veo así en alguien que también tiene una parte cultural de otro país, una mina que es paraguaya y aparte entiende guaraní, te sabe tocar el arpa, para mí es un plus y aparte que le guste, que lo diga, que no tenga vergüenza, mucho tiempo cuando yo era chico era tema de decir no, y tus papás de dónde son? Y mi mamá siempre nos decía y ustedes cuando les preguntan que dicen? Nos preguntaba a nosotros... a veces ella misma se contestaba antes de que nosotros digamos, o dudáramos "bien boliviano soy, tenés que decir...

Esa "doble identificación", cuando se presenta, puede beneficiar a estos hijos (mediante el manejo de dos códigos, lo que a su vez permite el ingreso a dos "mundos") aunque también puede ser perjudicial (debido a los altos niveles de discriminación a los que están expuestos desde niños ${ }^{41}$. En este sentido, suele ser más difícil para los hijos identificarse con el origen migratorio de los padres no solo debido a que muchos de ellos no han tenido contacto con lo que se considera la cultura boliviana, o ni siquiera han viajado a Bolivia; sino que además, porque en un contexto que los estigmatiza, la "adopción" de comportamientos vinculados a la supuesta cultura parental podría presentar obstáculos para su plena inserción social. Esto es así especialmente porque son vistos como un elemento distorsionador de la vida social del país que no termina de encajar en el modo en que la sociedad se imagina (o representa) a sí misma. En todo caso, sus experiencias no son sólo una continuación del involucramiento en la tierra de sus antepasados, sino que son principalmente producidas a partir del haber sido criados en un lugar diferente al de los padres.

\section{La "alterización" de los hijos y la escuela como "normalizadora"}

Si bien la escuela no reproduce de forma mecánica los procesos de discriminación y desigualdad que se encuentran en la sociedad, sí contribuye a enmascararlos y a naturalizarlos en el pensamiento cotidiano ${ }^{42}$. Al respecto, diversos estudios etnográficos han registrado un complejo panorama en aquellas escuelas de la Ciudad de Buenos Aires que cuentan con una cantidad significativa de niños nacidos en otros países ${ }^{43}$. Algunos de estos

${ }_{41}$ GAVAZZO, Hijos de bolivianos..., op. cit.

42 Ibidem; SINISI, Liliana. La relación "nosotros - otros" en espacios escolares multiculturales. Estigma, estereotipo y racialización.

${ }^{43}$ MONTESINOS, M. Paula e PALLMA, Sara. Contextos urbanos e instituciones escolares. Los usos del espacio y la construcción de la diferencia; MONTESINOS, M. Paula. Construyendo sentidos acerca de los procesos de desigualdad sociocultural en las escuelas. Un estudio acerca de los programas educativos focalizados; SINISI, op. cit.; DOMENECH, op. cit.; BEHERAN, El tratamiento de... op. cit.; DIEZ, NOVARO, Interculturalidad en educación..., op. cit.; MARTíNEZ, Discursos 
estudios señalan que los niños migrantes o los hijos de migrantes estudian en escuelas donde, a pesar de compartir el espacio con otros niños de recursos escasos, son percibidos como "otros"44. Es que uno de los mecanismos de la legitimación de su desigualdad es a través de la reproducción de los estereotipos negativos que provocan una marcación, una "alterización".

Como veíamos en uno de los trabajos ${ }^{45}$, los discursos y políticas públicas del Estado (como el argentino y el porteño) constituyen respuestas a los problemas que se suscitan con la inmigración que afectan la vida de estos hijos. Esto se observa no sólo en las políticas migratorias vigentes que determinan las posibilidades de permanencia de aquellos inmigrantes que tengan hijos argentinos ${ }^{46}$, sino también en las educativas, que asumen un papel activo en la constitución de esa subjetividad en tanto se encargan de la socialización de esos jóvenes como ciudadanos. En nuestro caso, ¿cómo son interpelados los hijos? ¿A partir de qué categorías son identificados y autoidentificados? ¿Se los concibe como argentinos o bolivianos?

La interpelación como "otros" funciona así como un disparador para la reflexión sobre la propia identidad. Al igual que sus padres bolivianos que fueron "rechazados" (o definidos como "no deseados") en los discursos oficiales argentinos durante la década del 90, algunos de estos hijos son percibidos como una continuidad de esa generación. A pesar de ser argentinos nativos, reciben-como si fuese una herencia- ese mismo estigma que fue legitimado por numerosos agentes estatales (instituciones y normativas legales, pero también políticas y discursos públicos), a pesar de que los esfuerzos actuales pretendan superarlo ${ }^{47}$. Esta situación se plantea como un área de "intervención" de la educación formal, especialmente con los migrantes y sus descendientes, pero en general con todos los niños y adolescentes argentinos que asisten a escuelas en las que se registra la vigencia de formas tradicionales del nacionalismo, más allá de la retórica de la inclusión y la interculturalidad tan ajustada a tiempos de discursos políticamente correctos ${ }^{48}$.

Para comprender esta intervención podríamos pensar en la biopolítica ${ }^{49}$, es decir en ese régimen de gobierno propio de la modernidad que opera

sobre la migración..., op. cit.; NOVARO, La interculturalidad..., op. cit.

${ }^{44}$ PORTES, op. cit.

${ }^{45}$ GAVAZZO, Hijos de bolivianos..., op. cit.

${ }^{46}$ Según la normativa migratoria actual e histórica la Argentina contempla el ius solis como criterio de ciudadanía, lo que garantiza una residencia permanente a los padres de personas nacidas en el territorio nacional.

${ }^{47}$ GAVAZZO, Hijos de bolivianos..., op. cit.

${ }^{48}$ NOVARO, Niños inmigrantes..., op. cit.

${ }^{49}$ FOUCAULT, Michael. La Gubernamentalidad. 
fundamentalmente mediante "intervenciones normalizadoras" sobre las poblaciones $^{50}$. Es una forma más que coercitiva, productora de subjetividades, una forma de gobierno de grandes poblaciones que está focalizada en saberes y prácticas constitutivos de regulación de la vida humana (como la moralidad, la lengua, la sexualidad, la alimentación, el cuidado de sí, la corporalidad, entre otros). Se plantea entonces, ¿̇los hijos de bolivianos deberían "argentinizarse" para "normalizarse"? ¿Que implicaría ello en términos concretos? ¿Qué rol desempeñan las escuelas en este sentido?

En todo caso es necesario preguntarse por el modo en que los hijos de inmigrantes son percibidos y "regulados" por ciertas normas sociales para ver no sólo las dificultades que enfrentan, sino el tratamiento que se hace de ellas ${ }^{51}$. Esto implica que la aceptación de las normas puede constituir una forma más o menos dada de la exclusión, y además, que la resignificación (los usos) de esas normas puede ser entendida en un sentido más práctico, como "negociación". Teniendo en cuenta las experiencias mencionadas hasta aquí referidas a las escuelas, parece que -aunque con diversos grados- los hijos de bolivianos que no pueden (o no quieren) desmarcarse de ese origen son definidos socialmente como "diferentes", es decir que son "alterizados". La demanda de "asimilación" que se deposita en ellos desde el nacionalismo escolar, como si fuesen una continuación de sus padres, vuelve a estos hijos "diferentes" de los demás nativos argentinos, con efectos heterogéneos en sus identificaciones y sentidos de pertenencia. Esta multiplicidad de identificaciones y sentidos de pertenencia que la mirada homogeneizadora sobre el otro no registra, es la que se procuró mostrar en el punto anterior a partir del examen de las perspectivas de los hijos.

\section{Reflexiones finales}

Este complejo entramado de factores muestra las heterogéneas formas de identificación de los hijos de bolivianos respecto de sus pertenencias, las culturas de sus padres y las identificaciones (y diferenciaciones) con ellos. Esto no deja lugar a una "simplificación" de la generación genealógica que es objeto de este trabajo (a saber, "los hijos"). Obliga a enfocar la mirada sobre los sujetos para poder recuperar -al menos- parte de esa heterogeneidad. ¿Qué define a los hijos como tales y los diferencia de sus padres más allá de la nacionalidad? Una posible respuesta a estas preguntas la encontramos en la intersubjetividad (entendida como la construcción colectiva de la subjetividad a partir de las interacciones con otros) implicada en las relaciones intergeneracionales entre

\footnotetext{
${ }^{50}$ Ibidem, p. 119.

${ }^{51}$ GARCÍA BORREGO, op. cit.
} 
inmigrantes y sus hijos, tal como se desprende de los relatos de los descendientes respecto de sus formas de identificarse (o no) con la "cultura de origen".

Justamente, la idea de "transmisión de una cultura de origen" de padres a hijos es errónea en tanto supone sin cuestionar una continuidad (casi generacional genética) de aspectos sociales y culturales ${ }^{52}$. Sin embargo, la construcción activa de una memoria común constituye un elemento fundamental de las relaciones entre padres e hijos en las familias migrantes. Aunque "desde afuera" se suele naturalizar ese vínculo (y adherirle entonces un conjunto de atributos y pertenencias), apoyados por el carácter biológico asignado tanto a la paternidad/maternidad como a la filiación, la diversidad de formas de identificación registradas demuestra que lo que entendemos por cultura se construye en cada apelación que se haga a ella, de acuerdo a quién la defina, cuándo y con qué fines ${ }^{53}$. Las fronteras entre culturas pueden o no coincidir con las fronteras de las identificaciones, las que son en todos los casos contextuales y situadas. Al mismo tiempo, lo que entendamos por ella responde a ciertas sedimentaciones y erosiones que permiten hablar de configuraciones con lógicas específicas que remiten a continuidades pero también a cambios cristalizados con el tiempo ${ }^{54}$. Estas lógicas permiten analizar a la generación de los hijos como un grupo social particular, con influencias similares (que son los significantes compartidos por padres e hijos) pero reapropiadas de modos específicos en cada sujeto (puesto que cada hijo construye significados propios). Es que las continuidades identitarias, cuando ocurren, si bien implican los mismos significantes, pueden resultar en significados diferentes para cada generación.

Resulta central destacar entonces que las identificaciones y las prácticas culturales de los hijos - como descendientes de inmigrantes bolivianos - son variadas y cambiantes, incluso llegando a expandirse a través de las fronteras nacionales, modificándose a través del tiempo e incluso reinventando el significado de algunas categorías para responder al estigma. En todo caso, en un contexto "europeizante", los hijos frecuentemente se ven interpelados como "otros" en muchos espacios y en particular en las escuelas (de lo que dan cuenta los relatos que aquí reproducimos), situación que constituye una imposición que no sólo los "marca" sino que restringe sus opciones de identificación y prácticas culturales a la identidad y la cultura de sus padres y parientes bolivianos. No existe "herencia" entonces, sino reinvención y reconstrucción permanente.

\footnotetext{
${ }^{52}$ GAVAZZO, Hijos de bolivianos..., op. cit.

${ }^{53}$ WRIGHT, Susan. La politización de la "cultura".

${ }^{54}$ GRIMSON, Alejandro. Los Límites de la Cultura.
} 
Sin embargo, las complejas y ambiguas experiencias que como generación tienen (entre otras las experiencias escolares) los posicionan en un lugar claramente distinto al de sus padres y los obligan a crear otra forma de estar y transitar la experiencia migrante.

\section{Bibliografía}

BEHERAN, Mariana. "A la vida siempre le tuve curiosidad... Siempre quise aprender y hacer cosas pero mi deseo es volver a mi país". Intersecciones entre experiencias formativas, transiciones laborales e identificaciones nacionales de jóvenes inmigrantes, y descendientes de inmigrantes, en la ciudad de Buenos Aires. Tesis doctoral, 2012.

. El tratamiento de la diversidad cultural en las escuelas públicas primarias de la ciudad de Buenos Aires. Tesis correspondiente a la Maestría en Políticas de Migraciones Internacionales. Buenos Aires: Universidad de Buenos Aires, 2007.

BORDEGARAY, Graciela; NOVARO, Gabriela. Diversidad y desigualdad en las políticas de Estado. Reflexiones a propósito del proyecto de Educación Intercultural y Bilingüe en el Ministerio de Educación. Cuadernos de Antropología Social, n. 19, 2004, p. 101-119.

BOURDIEU, Pierre. Algunas propiedades de los campos. In IDEM. Sociología y cultura. México: CONACULTA, 1990, p. 135-141.

. La distinción. Criterios y bases sociales del gusto. Madrid: Taurus 1999.

CHAVES, Mariana. Juventud negada y negativizada: representaciones y formaciones discursivas vigentes en la Argentina contemporánea. Revista Última Década, v. 13, n. 23, 2006, p. 9-32.

DEVOTO, Fernando. Historia de la inmigración a la Argentina. Buenos Aires: Paidós, 2003.

DIEZ, María Laura; HECHT, Ana; NOVARO, Gabriela; PADAWER, Ana. Interculturalidad y educación. Cruces entre la investigación y la gestión. In NOVARO, Gabriela (comp.). La interculturalidad en debate. Experiencias formativas y procesos de identificación en niños indígenas y migrantes. Buenos Aires: Editorial Biblos, 2011, p. 265-281.

DIEZ, María Laura; NOVARO, Gabriela. Interculturalidad en educación: ¿un abordaje para la crítica? Reflexiones a propósito de la escolarización de chicos migrantes bolivianos en Buenos Aires. In MELGAREJO, Patricia (comp.). Educación Intercultural en América Latina: memorias, horizontes históricos y disyuntivas políticas. México: Universidad Pedagógica Nacional, CONACIT, Plaza, 2009.

DOMENECH, Eduardo. Etnicidad e inmigración: ¿Hacia nuevos modos de integración en el espacio escolar?. Astrolabio, Centro de Estudios Avanzados, n. 1, 2004.

DONZELOT, Jacques. La policía de las familias. España: Pre-Textos, 1990.

ELIAS, Norbert. La civilización de los padres. In WEILER, Vera (comp.). La civilización de los padres y otros ensayos. Bogotá: Norma editorial, 1998.

ELÍAS, Norbert; SCOTSON, John. Os Estabelecidos e os Outsiders. Rio de Janeiro: Zahar, 1994. 
FONER, Nancy. Introduction: Intergenerational Relations in Immigrant Families. In Across Generation: Immigrant Families in America. NY: New York University Press, 2009.

FOUCAULT, Michael. La Gubernamentalidad. In AA.VV. Espacios de poder. Madrid: La Piqueta, 1991 [1978], p. 9-26.

GARCÍA BORREGO, Iñaki. Los hijos de inmigrantes extranjeros como objeto de estudio de la sociología. Anduli: revista andaluza de ciencias sociales, n. 3, 2003, p. 27-46.

GAVAZZO, Natalia. Para todos los hombres del mundo: diversidad cultural y nación en algunos discursos públicos sobre la inmigración en Argentina. In VIANA GARCES, Andrée (coord.). Repensar la Pluralidad. Madrid: Fundación Universidad Carlos II y Editorial Tirant Loblanch, 2009.

. Hijos de bolivianos y paraguayos en el área metropolitana de Buenos Aires. Identificaciones y participación, entre la discriminación y el reconocimiento. Tesis doctoral. Facultad de Filosofía y Letras. Universidad de Buenos Aires, 2012.

GOMEZ, S. Historias Nikkei, historias transnacionales. In IX Congreso Argentino de Antropología Social. Posadas, Argentina: Universidad Nacional de Misiones, 2008. GRIMSON, Alejandro. Los Límites de la Cultura. Buenos Aires: Siglo XXI, 2011.

KROPFF, Laura. Apuntes conceptuales para una antropología de la edad. Avá, revista de antropología, n. 16, 2008.

- Activismo mapuche en Argentina: trayectoria histórica y nuevas propuestas. In DÁVALOS, Pablo (comp.). Pueblos indígenas, estado y democracia. Ciudad Autónoma de Buenos Aires: CLACSO, 2005.

LAMOUNIER, I. Japanese Argentina Historial Overview. In Encyclopedia of Japanese in the Americas. An Illustrated History of the Nikkei. Ed. Akemi Kikumura. Yano, Japanese American National Museum, 2002, p. 72-82.

LEVITT, Peggy. Los desafíos de la vida familiar transnacional. In Grupo interdisciplinario de Investigador@s Migrantes (coord.). Familias, niños, niñas y jóvenes migrantes. Rompiendo estereotipos. Madrid: IEPALA, 2010.

LEVITT, Peggy; WATERS, Mary. The Changing Face of Home. The Transnational. New York: Russell Sage Foundation, 2002.

MALUENDRES, Sergio. De nuevo sobre las pautas matrimoniales de los migrantes y sus hijos piamonteses y leoneses en Trenel, Territorio Nacional de La Pampa, (19111940). Centro de Estudios Migratorios Latinoamericanos, n. 28, p. 449-480, 1994.

MANNHEIM, K. El problema de las Generaciones. Revista española de Investigaciones Sociológicas, REIS, n. 62, 1993 [1928], p. 193-242.

MARTÍN CRIADO, Enrique. Producir la juventud: crítica de la sociología de la juventud. Madrid: Istmo, 1998.

. "Generaciones/clases de edad" y "Juventud". In REYES, Román. Diccionario crítico de ciencias sociales. 2002. Publicación digital: < http://theoria.org/diccionario/>.

MARTÍNEZ, Laura. Discursos sobre la migración en el contexto escolar: una exploración de las relaciones entre las prácticas institucionales y las concepciones de los niños migrantes. In NOVARO, Gabriela (comp.). Niños indígenas y migrantes. Tensiones 
identitarias, experiencias formativas y procesos de escolarización. Buenos Aires: Editorial Biblos, 2011, p. 205- 224.

MONTESINOS, M. Paula. Construyendo sentidos acerca de los procesos de desigualdad sociocultural en las escuelas. Un estudio acerca de los programas educativos focalizados. Ponencia presentada en el VII Congreso Argentino de Antropología Social, Oficio antropológico y compromiso social en las crisis. Villa Giardino, Córdoba, 2004. MONTESINOS, M. Paula; PALLMA, Sara. Contextos urbanos e instituciones escolares. Los usos del espacio y la construcción de la diferencia. In NEUFELD, María Rosa; THISTED, Jean Ariel (comps.). De eso no se habla. Los usos de la diversidad sociocultural en la escuela. Buenos Aires: EUDEBA, 1999, p. 57-90.

NEUFELD, María Rosa; THISTED, Jean Ariel (comps.). De eso no se habla: los usos de la diversidad sociocultural en la escuela. Buenos Aires: EUDEBA, 1999.

NOVARO, Gabriela (coord.). La interculturalidad en debate. Experiencias formativas y procesos de identificación en niños indígenas y migrantes. Buenos Aires: Editorial Biblos, 2011.

(en prensa). Procesos de identificación nacional en población migrante: continuidades y quiebres en las relaciones intergeneracionales. Revista de Antropología Social, Universidad Complutense de Madrid, 2012.

. Niños inmigrantes en Argentina: nacionalismo escolar, derechos educativos y experiencias de alteridad. Revista Mexicana de Investigación Educativa, v. 17, n. 53, 2012.

NOVARO, Gabriela; BORTON, Laureano; DIEZ, María Laura; HECHT, Ana. Sonidos del silencio, voces silenciadas. Niños indígenas y migrantes en escuelas de Buenos Aires. Revista Mexicana de Investigación Educativa, v. 13, n. 36, 2008.

NOVARO, Gabriela; DIEZ, María Laura. ¿Una inclusión silenciosa o las sutiles formas de la discriminación? Reflexiones a propósito de la escolarización de chicos bolivianos. In COURTIS, Corina; PACECCA, María Inés (comps.). Discriminaciones étnicas y nacionales. Un diagnóstico participativo. Buenos Aires: Editores del Puerto, 2012.

ONAHA, Cecilia. Japoneses en Argentina y nikkei argentinos en Japón: el rol de la identidad nacional y étnica en un proceso de integración de los nikkei argentinos en Okinawa. In X Congreso Internacional ALADAA, Río de Janeiro, 2000.

PEDONE, Claudia. Introducción. Más allá de los estereotipos: desafíos en torno al estudio de las familias migrantes. In GIIM (coord.). Familias, niños, niñas y jóvenes migrantes. Rompiendo estereotipos. España: IEPALA, 2010.

PEDREÑO CANOVAS, Andrés. Carrera y fracaso en las trayectorias sociales de los hijos de inmigrantes. In Tránsitos migratorios: contextos transnacionales y proyectos familiares en las migraciones actuales. España: Ediciones de la Universidad de Murcia, 2010.

PORTES, Alejandro (ed.). The Economic Sociology of Immigration. Essays on Networks, Ethnicity and Entrepreneurship. New York: Russell Sage Foundation, 1997.

PORTES, Alejandro; RUMBAUT, Rubén. Immigrant America: a portrait. Berkeley: University of California Press,1996.

. Legacies: the Story of the Immigrant. Second Generation. Nueva York: Russell Sage Foundation, 2001. 
PORTES, Alejandro; ZHOU, Min. En route vers les sommets: nouvelles perspectivas sur la question des minorités ethniques. Revue Européenne des Migrations Internationales, v. 8, n. 1, 1992, p. 171-192.

SAYAD, Abdelmalek. La doble ausencia. De las ilusiones del emigrado a los padecimientos del inmigrado. Buenos Aires: Anthropos, 2011.

SINISI, Liliana. La relación "nosotros-otros" en espacios escolares multiculturales. Estigma, estereotipo y racialización. In NEUFELD, M. Rosa; THISTED, Ariel (coords.). "De eso no se habla....". Los usos de la diversidad en la escuela. Buenos Aires: Eudeba, 1999.

WRIGHT, Susan. La politización de la "cultura". Anthropology Today, v. 14. n. 1, 1998, p. 7-15.

\section{Abstract \\ Schooling as a milestone in the biographies of Bolivian children in Buenos Aires}

This project is the result of three works of research conducted using social anthropological methods to analyze the experiences of the children of Bolivian immigrants in different areas of the city of Buenos Aires and the Province of Buenos Aires. Beginning with the study of the migratory processes from Bolivia and their changes throughout generations, we intend to posit that schooling constitutes a fundamental part of the experiences of children, young migrants and especially the descendents of Bolivian immigrants. Given that this affects their intellectual development, and above all, their national, ethnic, gender, class, and age identifications, we will focus on understanding the role of schooling during this vital stage of youth. Keeping in mind some of the most common representations in the examined cases, we will show that the passage through primary and secondary school is a milestone in the biographies of the children, youth, and descendants of Bolivians who have been raised in Buenos Aires, and we will analyze the impact in their methods of identification and their relationships.

Keywords: youth, migration, education, identification.

Recebido para publicación en 03/03/2014.

Aceptado para publicación en 22/05/2014.

Received for publication in March, 03 ${ }^{\text {th }}, 2014$.

Accepted for publication in May, 22 $2^{\text {th }}, 2014$. 